\title{
Homocysteine, Cysteine, and Related Metabolites in Maternal and Fetal Plasma in Preeclampsia
}

\author{
KRISTIN BRAEKKE, PER MAGNE UELAND, NINA KITTELSEN HARSEM, ANETTE KARLSEN, RUNE BLOMHOFF, \\ AND ANNE CATHRINE STAFF
}

\begin{abstract}
Department of Pediatric Intensive Care [K.B.], Ulleval University Hospital, 0407 Oslo, Norway; Section for Pharmacology [P.M.U.], LOCUS for Homocysteine and Related Vitamins, Institute of Medicine, University of Bergen, 5020 Bergen, Norway; Department of Obstetrics and Gynecology [N.K.H, A.C.S.], Ulleval University Hospital and Faculty of Medicine, 0407 Oslo, Norway; Department of Nutrition [A.K., R.B.], Institute of Basic Medical Science, University of Oslo, 0316 Oslo, Norway
\end{abstract}

\begin{abstract}
Homocysteine is associated with endothelial dysfunction and cardiovascular disease, and elevated concentrations of homocysteine have been found in preeclampsia. The purpose of this study was to investigate maternal and fetal concentrations of total homocysteine and related metabolites (including cysteine, choline, and betaine), and possible associations with infant birth weight. Women with preeclampsia $(n=47)$ and controls $(n=51)$, who underwent cesarean section, were included. Maternal plasma, umbilical vein, and artery plasma were analyzed. Median concentrations of homocysteine, cysteine, choline, and betaine were significantly higher in women with preeclampsia than controls, both in maternal and fetal plasma. There were no differences in folate and vitamin $\mathrm{B}_{12}$ concentrations between the groups, neither for maternal nor fetal samples. Maternal homocysteine concentration was a negative predictor for birth weight only in the preeclampsia group. Elevated homocysteine and cysteine concentration in maternal circulation in preeclampsia is reflected in the fetal circulation. The clinical significance of elevated homocysteine and cysteine concentrations in maternal and fetal compartments in preeclampsia remain to be explored, both regarding fetal growth and development of disease later in life. (Pediatr Res 62: 319-324, 2007)
\end{abstract}

$\mathrm{P}$ reeclampsia is defined as the combination of pregnancyinduced hypertension and proteinuria in the second half of the pregnancy. A dominating hypothesis is that agents produced by a relatively hypoxic placenta are transferred to the maternal circulation, causing endothelial dysfunction, and thereby maternal hypertension and proteinuria (1). For both mother and infant, the syndrome may have both short- and long-term consequences, including cardiovascular disease later in life (2).

High circulating levels of homocysteine can cause endothelial dysfunction (3), and elevated plasma concentrations of homocysteine and cysteine are associated with cardiovascular disease $(4,5)$. Cysteine is also associated with endothelial dysfunction, but in contrast to homocysteine, its concentration is not predicted by vitamin $\mathrm{B}_{12}$ and folate (5). In uncomplicated pregnancies, high maternal homocysteine concentration has been associated with low birth weight in offspring $(6,7)$.

Received February 21, 2007; accepted April 17, 2007.

Correspondence: Kristin Braekke, M.D., Department of Pediatric Intensive Care, Ulleval University Hospital, Kirkeveien 166, 0407 Oslo, Norway; e-mail: kbre@uus.no, krb@broadpark.no
Elevated maternal concentrations of homocysteine or cysteine have been reported in preeclampsia (8-10), and increased homocysteine concentrations have also been detected before clinical symptoms $(11,12)$. The relationship might not be causal (13), but these aminothiols could still have potential deleterious effects, not only on the maternal endothelium, but also on the fetus.

Homocysteine is a sulfur-containing amino acid that can be converted to cystathionine and further to cysteine via the transsulfuration pathway or remethylated to methionine (Fig. 1). The latter reaction is catalyzed by methionine synthase in most tissues. In this reaction, vitamin $\mathrm{B}_{12}$ (cobalamin) serves as cofactor and folate (5-metyltetrahydrofolate) as substrate. In the liver and kidney, an additional pathway for homocysteine remethylation exists, requiring betaine as a methyl donor. Choline is the immediate metabolic precursor of betaine (Fig. 1) (14). Choline is involved in membrane biosynthesis and acetylcholine formation and is regarded as a critical nutrient in fetal development and neurotransmission (15). Recently, reports on choline and betaine concentrations at delivery (16), and longitudinal data in normal pregnancy have been published (17), but studies on these metabolites have to our knowledge not previously been investigated in preeclampsia (13).

The aim of this study was to investigate maternal and fetal concentrations of total homocysteine and related metabolites of the homocysteine pathway (including cysteine, choline, and betaine) in pregnancies complicated by preeclampsia compared with uncomplicated pregnancies. We also explored whether homocysteine and related metabolites were associated with infant birth weight percentiles.

\section{METHODS}

Protocol. In this study, we included women with preeclampsia $(n=47)$ and uncomplicated pregnancies (controls, $n=51$ ), all singleton pregnancies, delivery by cesarean section, providing maternal and fetal (umbilical cord) blood. All the women were fasting and were not in active labor, and none had rupture of membranes or signs of infection. Cesarean section was performed

Abbreviations: BHMT, betaine-homocysteine methyltransferase; DMG, dimethylglycine; HPLC, high-performance liquid chromatography; MTHFR, methylenetetrahydrofolate reductase; SGA, small for gestational age; tCys, total cysteine; tHcy, total homocysteine 


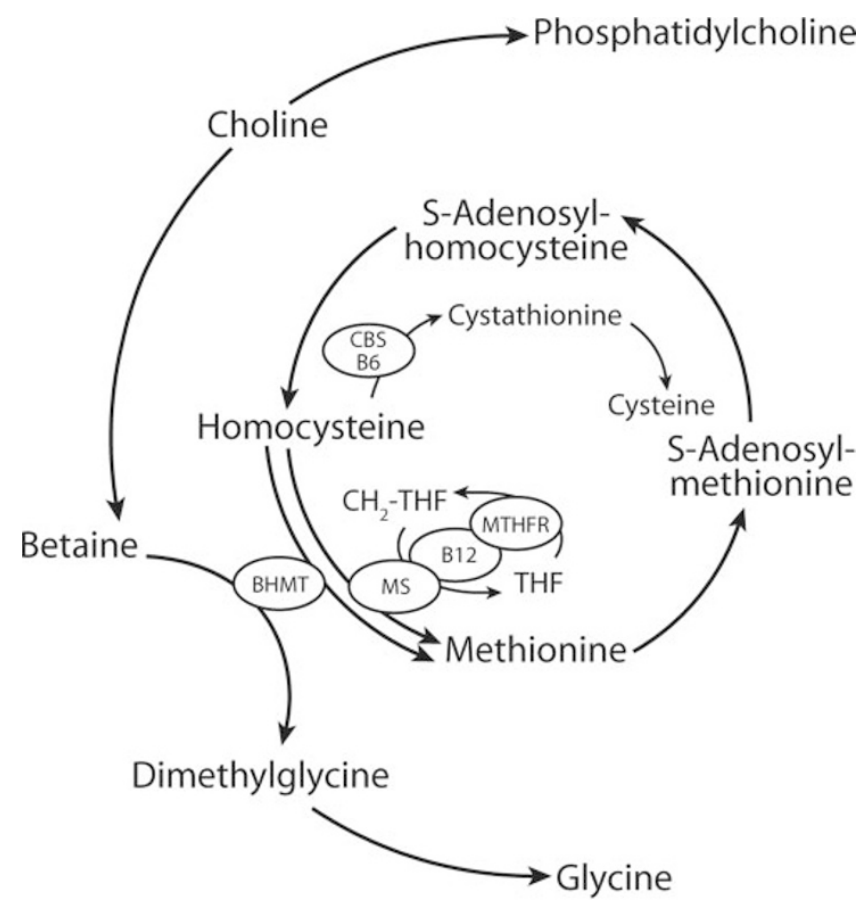

Figure 1. Metabolism of homocysteine. BHMT, betaine homocysteine methyltransferase; $\mathrm{CH}_{2}$-THF, 5-metyltetrahydrofolate (folate); $\mathrm{MS}$, methionine synthase; MTHFR methylenetetrahydrofolate reductase; THF, tetrahydrofolate; CBS, cystathionine beta-synthase.

in the preeclamptic women because vaginal delivery was not considered appropriate due to disease progression and/or unfavorable cervical ripening. Controls were healthy, normotensive women undergoing cesarean section due to breech presentation, previous cesarean section, or psychological reasons. The study is part of an ongoing biobank collection at Ulleval University Hospital (18).

Preeclampsia was defined as an increase in blood pressure above140/90 after gestational wk 20 on at least two occasions $6 \mathrm{~h}$ apart in a previously normotensive woman, combined with proteinuria. Proteinuria was defined as protein dipstick reading $\geq 1+$ on more than one midstream urine sample $6 \mathrm{~h}$ apart or a 24 -h urine excretion of $\geq 0.3 \mathrm{~g}$ protein in the absence of urinary infection.

Pregnancy duration was calculated based on routine ultrasound screening between gestational wk 17 and 20. Medical history and obstetric information were obtained from medical records and the patients' national pregnancy charts, as well as by interviewing the patients. The infants' weight percentiles were estimated from weight curves based on longitudinal ultrasound measurements of a population of healthy pregnant Norwegian women (19). Infants below the 10th percentile were defined as small for gestational age (SGA). The study protocol was approved by the Regional Committee of Medical Ethics in Eastern Norway, and informed written consent was obtained from each woman.

Biologic samples. Maternal blood samples were obtained before cesarean section. The umbilical cord was double clamped near the placenta and near the infant and immediately after delivery of the placenta; blood from the umbilical arteries (transporting blood from the fetus to the placenta) and blood from the umbilical vein (transporting blood from the placenta to the fetus) was sampled separately into ethylenediaminetetraacetic acid (EDTA)-containing vials. Samples were kept on ice for a maximum of $30 \mathrm{~min}$ and centrifuged at $4^{\circ} \mathrm{C}$ for $10 \mathrm{~min}$ at $2000 \times \mathrm{g}$, and plasma was stored in aliquots at $-76^{\circ} \mathrm{C}$ until assayed. The laboratory personnel were blinded to clinical information.

Biochemical analyses. Total homocysteine (tHcy) concentration was measured in EDTA plasma by high-performance liquid chromatography (HPLC), as described by Bohn et al. (20), using a homocysteine kit from Bio-Rad (Bio-Rad Laboratories, Munich, Germany) essentially as described by the manufacturer, except that all volumes were scaled down by a factor of 2 . The inter- and intra-assay coefficients of variation (CVs) were $4 \%$ and $2 \%$.

Plasma levels of vitamin $B_{12}$ (21) and folate (22) were determined by microbiological assays using a chloramphenicol-resistant strain of Lactobacillus casei and a colistin sulfate-resistant strain of Lactobacillus leichmannii, respectively. Both assays were adapted to a microtiter plate format and carried out by a robotic workstation. For these microbiological assays, inter- and intra-assay CVs were 5\% and 4\%, respectively.

Methionine, total cysteine (tCys), cystathionine, choline, betaine, and dimethylglycine (DMG) concentrations were measured in EDTA plasma using normal-phase liquid chromatography and tandem mass spectrometry (23).The within- and between-day imprecision CVs for all three metabolites were between $2 \%$ and $9 \%$.

Statistics. Because not all the values were normally distributed, medians are reported and Mann-Whitney $U$ test and Wilcoxon signed rank test were used for testing differences between groups. Regression analyses are presented on nontransformed values. When values were $\ln$ transformed, the results came out essentially the same. Statistical analyses, including Spearman's correlation and regression analyses, were performed using Statistical Package for the Social Sciences (version 14.0; SPSS Inc, Chicago, IL). A probability level of $\leq 0.05$ was considered statistically significant.

\section{RESULTS}

Study population and biochemical variables. The clinical characteristics of the patient groups are summarized in Table 1. Median gestational age at delivery and infant birth weight (absolute and percentile) were lower in the preeclampsia group. A higher proportion of infants were SGA in the preeclampsia group.

Maternal and fetal (both umbilical vein and artery) plasma concentrations of homocysteine, related metabolites, and B vitamins are reported in Table 2. For technical reasons, we did not get all samples for all patients from all three compartments; the exact sample numbers are given in Table 2. Median concentrations of tHcy, tCys, choline, and betaine were significantly higher in preeclampsia compared with controls both for maternal and fetal plasma. No differences were found in folate and vitamin $B_{12}$ concentrations between the groups nor for maternal or fetal samples (Table 2). Differences between maternal and fetal values for all biochemical variables were highly significant $(p<0.001)$.

There were no significant correlations between maternal tHcy or tCys and maternal age or between tHcy or tCys and BMI (neither before pregnancy nor at delivery) (data not shown). In a simple correlation, birth weight percentile was associated with tHcy in the whole group $(r=0.43, p<0.001)$ and in the preeclampsia group $(r=0.78, p=0.10)$ but not in the control group when analyzed separately $(r=-0.11, p=$ $0.48)$.

There were no statistically significant differences in maternal concentrations of tHcy, tCys, choline, or betaine between

Table 1. Patient characteristics

\begin{tabular}{lccc}
\hline & $\begin{array}{c}\text { Preeclampsia } \\
(n=47)\end{array}$ & $\begin{array}{c}\text { Controls } \\
(n=51)\end{array}$ & $p$ \\
\hline Maternal age, y & $31.5(19-42)$ & $32.5(21-44)$ & 0.76 \\
BMI before pregnancy, & $24.1(18.9-41.1)$ & $22.5(17.4-29.4)$ & $0.01^{*}$ \\
kg/m & & & \\
BMI at delivery, kg/m & $30.9(21.2-45.9)$ & $28.1(20.3-37.5)$ & $0.01^{*}$ \\
Gestational age, d & $230(174-271)$ & $271(241-292)$ & $<0.001^{*}$ \\
BP at delivery, systolic & $160(145-220)$ & $120(90-140)$ & $<0.001^{*}$ \\
BP at delivery, diastolic & $102(90-119)$ & $70(60-92)$ & $<0.001^{*}$ \\
Birth weight, kg & $1.72(0.87-3.86)$ & $3.47(2.80-4.68)$ & $<0.001^{*}$ \\
Birth weight percentile & $7(1-92)$ & $69(6-99)$ & $<0.001^{*}$ \\
Percentage SGA & 60 & 6 & $<0.001^{*}$ \\
\hline
\end{tabular}

Values are presented as medians and range (minimum and maximum values) except for percentage SGA. BMI, body mass index; BP, blood pressure.

$* p<0.05$. 
Table 2. Plasma concentrations of biochemical variables in maternal circulation, umbilical vein, and umbilical artery for the preeclampsia and control groups

\begin{tabular}{|c|c|c|c|}
\hline \multirow[b]{2}{*}{$\begin{array}{c}\text { Biochemical } \\
\text { variables }\end{array}$} & \multicolumn{3}{|c|}{ Maternal plasma } \\
\hline & $\begin{array}{c}\text { PE } \\
(n=43)\end{array}$ & $\begin{array}{c}\mathrm{Ctr} \\
(n=40)\end{array}$ & $p$ \\
\hline tHcy $(\mu \mathrm{mol} / \mathrm{L})$ & $8.2(6.2-11.5)$ & $6.4(5.4-7.7)$ & $<0.001 *$ \\
\hline Folate $(\mathrm{nmol} / \mathrm{L})$ & $6.6(4.7-10.9)$ & $6.4(4.6-11.9)$ & 0.97 \\
\hline Vitamin $B_{12}(\mathrm{pmol} / \mathrm{L})$ & $186(136-286)$ & $171(130-193)$ & 0.11 \\
\hline Methionine $(\mu \mathrm{mol} / \mathrm{L})$ & $26.3(23.9-31.1)$ & $22.2(20.4-24.4)$ & $<0.001^{*}$ \\
\hline tCys $(\mu \mathrm{mol} / \mathrm{L})$ & $256(220-308)$ & $191(177-215)$ & $<0.001 *$ \\
\hline Cystathionine $(\mu \mathrm{mol} / \mathrm{L})$ & $0.28(0.24-0.35)$ & $0.23(0.20-0.30)$ & $0.016^{*}$ \\
\hline Choline $(\mu \mathrm{mol} / \mathrm{L})$ & $8.8(7.5-10.4)$ & $7.3(7.5-9.0)$ & $0.001 *$ \\
\hline Betaine $(\mu \mathrm{mol} / \mathrm{L})$ & $11.7(9.7-13.1)$ & $9.95(8.9-11.6)$ & $0.002 *$ \\
\hline $\mathrm{DMG}(\mu \mathrm{mol} / \mathrm{L})$ & $2.8(2.8-3.9)$ & $2.6(2.0-3.1)$ & 0.064 \\
\hline \multirow[t]{2}{*}{ Creatinine $(\mu \mathrm{mol} / \mathrm{L})$} & $59.9(52.2-69.8)$ & $51.4(45.9-58.6)$ & $0.001 *$ \\
\hline & \multicolumn{3}{|c|}{ Umbilical vein plasma } \\
\hline
\end{tabular}

\begin{tabular}{lccc}
\cline { 2 - 4 } \multicolumn{1}{c}{$\begin{array}{c}\text { Biochemical } \\
\text { variables }\end{array}$} & $\begin{array}{c}\mathrm{PE} \\
(n=38)\end{array}$ & $\begin{array}{c}\mathrm{Ctr} \\
(n=46)\end{array}$ & \multicolumn{1}{c}{$p$} \\
\hline tHcy $(\mu \mathrm{mol} / \mathrm{L})$ & $6.5(5.0-8.3)$ & $5.2(4.5-6.5)$ & $0.006^{*}$ \\
Folate $(\mathrm{nmol} / \mathrm{L})$ & $16.4(12.6-19.9)$ & $17.6(14.6-26.0)$ & 0.11 \\
Vitamin $\mathrm{B}_{12}(\mathrm{pmol} / \mathrm{L})$ & $275(203-429)$ & $229(180-308)$ & 0.09 \\
Methionine $(\mu \mathrm{mol} / \mathrm{L})$ & $32.8(28.3-36.6)$ & $30.3(28.9-33.0)$ & 0.09 \\
tCys $(\mu \mathrm{mol} / \mathrm{L})$ & $196(166-246)$ & $172(151-191)$ & $0.001^{*}$ \\
Cystathionine $(\mu \mathrm{mol} / \mathrm{L})$ & $0.44(0.31-0.67)$ & $0.35(0.26-0.42)$ & $0.005^{*}$ \\
Choline $(\mu \mathrm{mol} / \mathrm{L})$ & $32.7(27.1-44.8)$ & $24.7(21.6-28.2)$ & $<0.001^{*}$ \\
Betaine $(\mu \mathrm{mol} / \mathrm{L})$ & $30.1(26.8-32.7)$ & $24.6(21.9-29.2)$ & $<0.001^{*}$ \\
DMG $(\mu \mathrm{mol} / \mathrm{L})$ & $4.1(3.3-6.0)$ & $4.1(3.6-5.1)$ & 0.69 \\
Creatinine $(\mu \mathrm{mol} / \mathrm{L})$ & $59.7(53.0-66.7)$ & $51.1(47.6-57.4)$ & $0.001^{*}$
\end{tabular}

Umbilical artery plasma

\begin{tabular}{lccc}
\multicolumn{1}{c}{$\begin{array}{c}\text { Biochemical } \\
\text { variables }\end{array}$} & $\begin{array}{c}\text { PE } \\
(n=26)\end{array}$ & $\begin{array}{c}\text { Ctr } \\
(n=32)\end{array}$ & $p$ \\
\hline tHcy $(\mu \mathrm{mol} / \mathrm{L})$ & $5.7(4.9-7.8)$ & $4.9(4.2-5.7)$ & $0.009^{*}$ \\
Folate $(\mathrm{nmol} / \mathrm{L})$ & $16.2(14.0-23.5)$ & $17.4(14.0-22.8)$ & 0.79 \\
Vitamin $\mathrm{B}_{12}(\mathrm{pmol} / \mathrm{L})$ & $247(187-402)$ & $244(189-344)$ & 0.84 \\
Methionine $(\mu \mathrm{mol} / \mathrm{L})$ & $29.1(27.0-32.0)$ & $27.3(26.2-29.3)$ & 0.077 \\
tCys $(\mu \mathrm{mol} / \mathrm{L})$ & $191(152-212)$ & $165(137-181)$ & $0.021^{*}$ \\
Cystathionine $(\mu \mathrm{mol} / \mathrm{L})$ & $0.46(0.33-0.80)$ & $0.32(0.26-0.42)$ & $0.005^{*}$ \\
Choline $(\mu \mathrm{mol} / \mathrm{L})$ & $33.3(24.5-41.0)$ & $22.4(20.5-24.4)$ & $<0.001^{*}$ \\
Betaine $(\mu \mathrm{mol} / \mathrm{L})$ & $31.3(26.0-37.7)$ & $26.0(23.5-29.7)$ & $0.011^{*}$ \\
DMG $(\mu \mathrm{mol} / \mathrm{L})$ & $3.8(3.3-4.7)$ & $4.1(3.1-4.8)$ & 0.59 \\
Creatinine $(\mu \mathrm{mol} / \mathrm{L})$ & $60.6(52.1-69.7)$ & $51.0(47.3-56.9)$ & $0.005^{*}$ \\
\hline
\end{tabular}

Values are presented as median and interquartile range.

$* p<0.05$.

early-onset $(n=30)$ and late-onset $(n=13)$ preeclampsia (delivered before or after gestational wk 34), or severe $(n=$ $33)$ and nonsevere $(n=10)$ preeclampsia, as defined by American College of Obstetricians and Gynecologists (24) (data not shown).

Associations between metabolites. The median umbilical artery and vein concentrations of measured vitamins and metabolites were quite similar (Table 2), and there was a high correlation for the concentrations of all the analyzed biochemical variables between the umbilical vein and artery (Spearman's correlations between 0.60 and 0.91 ). Therefore, the analyses presented below, including those presented in Table 3 and Table 4, include only umbilical vein concentrations. Spearman's correlations between various metabolites in ma- ternal and fetal plasma are presented separately for the preeclampsia and control groups in Table 3 and Table 4.

In both preeclampsia and normal pregnancy, the correlations between the maternal and fetal concentrations were significant $(r>0.37)$ for tHcy, folate, vitamin $\mathrm{B}_{12}$, tCys, and creatinine, but not for choline and betaine.

In the maternal circulation, tHcy was inversely correlated to folate and vitamin $\mathrm{B}_{12}$ and positively to creatinine in controls, whereas in preeclampsia, the negative association between folate and tHcy was present, but there was no significant correlation between tHcy and vitamin $\mathrm{B}_{12}$ or creatinine. In both groups, choline was positively related to betaine and creatinine, and tCys was positively related to creatinine (Table 3 and Table 4).

In the fetal circulation, tHcy was inversely correlated to vitamin $\mathrm{B}_{12}$ and positively to creatinine in controls, but in preeclampsia, the tHcy-creatinine association was absent, as seen in the maternal circulation. In both groups, choline correlated positively with betaine, whereas the association between choline and creatinine was of borderline significance (Table 3 and Table 4).

Predictors of maternal and fetal tHcy. Statistical predictors of maternal tHcy were evaluated in a multiple regression model (Table 5), including maternal folate, vitamin $B_{12}$, choline, betaine, and creatinine. In the preeclampsia group, only folate concentration was a significant negative predictor of tHcy concentrations. In the control group, folate, vitamin $\mathrm{B}_{12}$, and betaine were negative predictors, and creatinine was a positive predictor for tHcy.

When determinants of fetal tHcy were investigated in a multiple regression model including maternal concentrations of tHcy and fetal folate, vitamin $\mathrm{B}_{12}$, betaine, and creatinine, only maternal tHcy came out as a significant predictor (preeclampsia group: adjusted $\beta=0.44, p=0.025$, control group: adjusted $\beta=0.53, p=0.004$ ).

Birth weight and SGA. Maternal predictors of infant weight percentile were investigated by a backward multiple regression model that initially included maternal tHcy, folate, vitamin $B_{12}$, methionine, tCys, cystathionine, choline, betaine, and creatinine. Variables were removed from the model using as threshold the probability level of 0.1 . For the whole group tCys $(\beta=-0.39, p=0.001)$ and tHcy $(\beta=-0.21, p=0.07)$ were retained in the model as the strongest predictors, whereas for the preeclampsia group, only tHcy $(\beta=-0.32, p=0.04)$ was a predictor of neonatal birth weight percentile.

In the preeclampsia group, $60 \%$ of the infants were classified as SGA. When the preeclampsia group was analyzed for the subgroups of SGA and non-SGA, we found that both maternal tHcy and tCys were higher in the SGA group $(n=$ $28)$ than in the non-SGA group $(n=15)$ (tHcy: 9.1 versus 6.3 $\mu \mathrm{M}, p=0.013$; tCys: 272 versus $222 \mu \mathrm{M}, p=0.045)$. There was no difference between SGA and non-SGA in the preeclampsia group regarding maternal choline concentration (8.6 versus $9.1 \mu \mathrm{M}, p=0.46$ ). For infants in the preeclampsia group, there was a significant difference in choline concentrations in the umbilical vein between SGA and non-SGA (43.6 versus $29.4 \mu \mathrm{M} ; p=0.006$ ).

We also assessed the risk of the outcome variable SGA by a backward logistic regression analysis, which included 
Table 3. Spearman correlation coefficients between tHcy and related metabolites in maternal and fetal (umbilical vein) plasma: preeclampsia

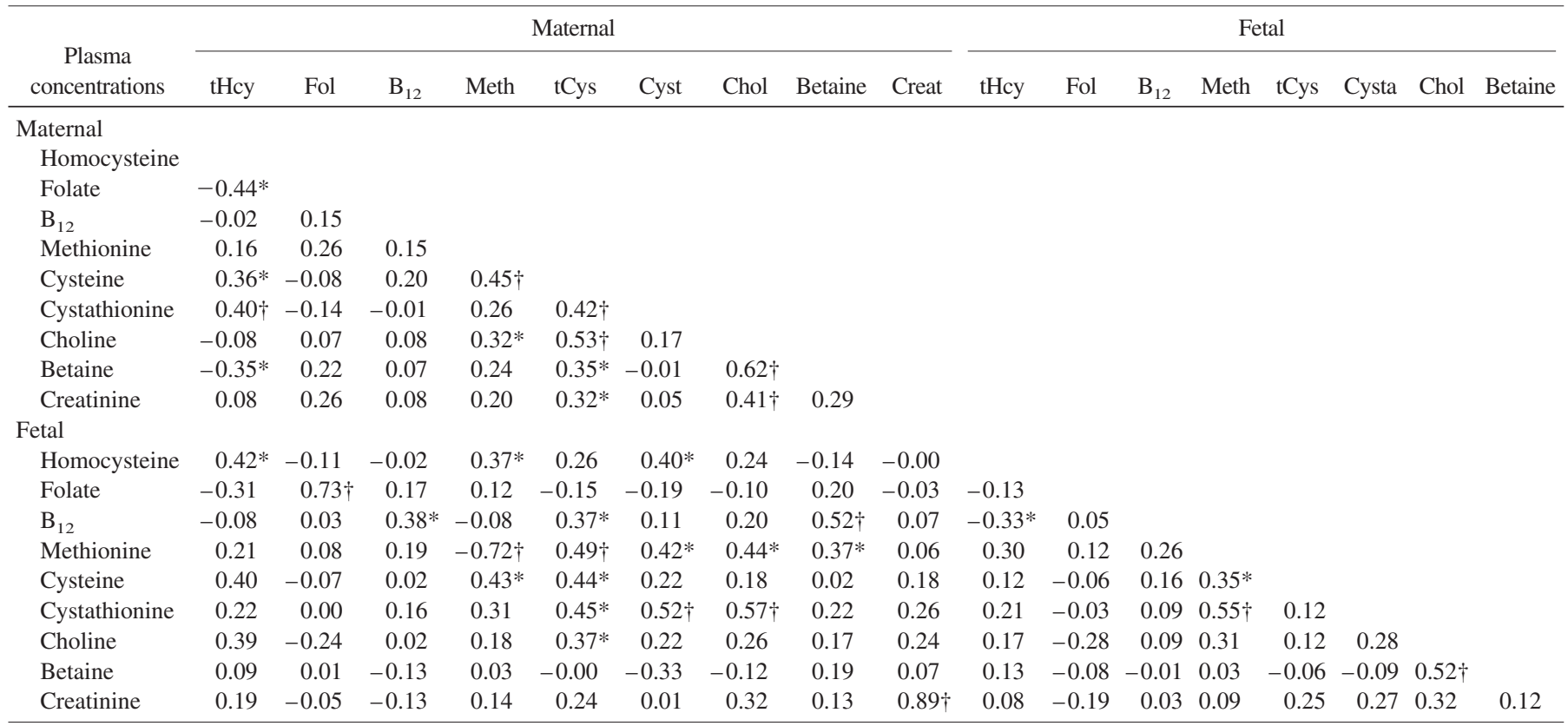

$* p<0.05 ; \dagger p<0.01$.

Fol, folate; $\mathrm{B}_{12}$, vitamin $\mathrm{B}_{12}$; Meth, methionine; Chol, choline; Creat, creatinine.

Table 4. Spearman correlation coefficients between tHcy and related metabolites in maternal and fetal (umbilical vein) plasma: controls

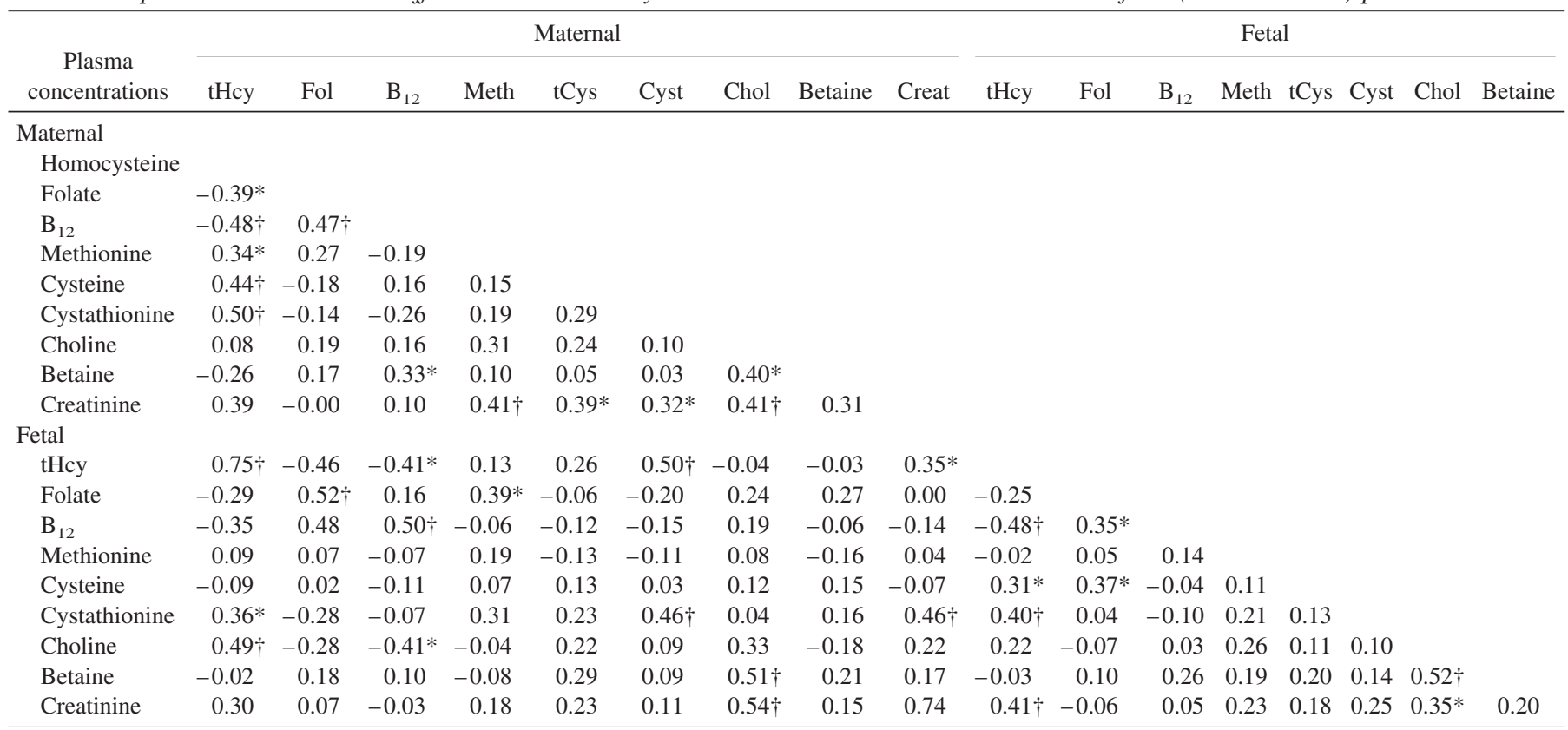

$* p<0.05 ; \dagger p<0.01$.

as predictor variables the same maternal indices as in the model above. The analysis was confined to the preeclampsia group, which included 28 of the 31 SGA infants in the study. Only tHcy was retained as a significant risk factor for SGA (odds ratio $=1.53,95 \%$ confidence interval: $1.04-$ 2.27, $p=0.03)$.

\section{DISCUSSION}

In this study, we found that median concentrations of plasma tHcy, but also tCys, choline, and betaine were elevated both in maternal and fetal compartments in preeclampsia compared with uncomplicated pregnancies. Folate and vita-
Table 5. Determinants of maternal tHcy in preeclampsia patients and controls by multiple regression (all parameters were simultaneously present in the model)

\begin{tabular}{lccccc}
\hline & \multicolumn{2}{c}{ Preeclampsia } & & \multicolumn{2}{c}{ Controls } \\
\cline { 2 - 3 } \cline { 5 - 6 } $\begin{array}{l}\text { Independent variables } \\
\text { maternal factors }\end{array}$ & $\begin{array}{c}\beta \\
\text { (adjusted) }\end{array}$ & $p$ & & $\begin{array}{c}\beta^{2} \\
\text { (adjusted) }\end{array}$ & $p$ \\
\hline Folate & -0.48 & $0.006^{*}$ & & -0.34 & $0.04^{*}$ \\
Vitamin $B_{12}$ & 0.18 & 0.24 & & -0.32 & $0.03^{*}$ \\
Choline & -0.17 & 0.44 & & 0.19 & 0.26 \\
Betaine & -0.003 & 0.99 & & -0.34 & $0.02^{*}$ \\
Creatinine & 0.32 & 0.06 & & 0.37 & $0.02^{*}$ \\
\hline
\end{tabular}

$* p<0.05$. 
min $B_{12}$ concentrations did not differ between the preeclampsia and control groups. In the preeclampsia group, we found an inverse association between tHcy and birth weight percentiles, and tHcy concentration was a predictor for SGA.

In normal pregnancies, tHcy concentrations are lower in the second than in the first trimester and increase toward nonpregnant values in the second half of the third trimester (25). The reduced tHcy concentration in pregnancy is not explained by hemodilution, folic acid supplementation, or decreased albumin (6), nor can it be fully explained by alterations in renal handling of homocysteine (26).

The etiology of the higher tHcy plasma concentrations in preeclamptic pregnancies is not known. Studies of methylenetetrahydrofolate reductase (MTHFR) polymorphisms, folate, and vitamin $B_{12}$ have failed to prove these to be of significant impact [reviewed in Mignini et al. (13)]. Metabolism of homocysteine along the betaine-homocysteine methyltransferase (BHMT) pathway could be more important than folate-dependent metabolism in late pregnancy $(17,27)$. Therefore, elevated maternal homocysteine concentrations in preeclampsia could theoretically have been caused by insufficient availability of betaine and choline. Our study, on the contrary, showed that both choline and betaine concentrations in the maternal as well as in the fetal compartment were significantly elevated in preeclamptic pregnancies compared with healthy controls. Choline concentrations were three to four times higher in the fetal than in the maternal circulation both for preeclampsia and control groups, which is in accordance with a previous study of normal pregnancies (16). In contrast to the Molloy et al. (16) study, we did not find any correlation between homocysteine and choline concentrations in the maternal compartment in the control or the preeclampsia group (Table 3 and Table 4).

Interestingly, we found no difference between preeclampsia and controls regarding median plasma folate concentrations, but folate was a stronger predictor of tHcy in preeclampsia than controls. In Norway, food is not fortified with folic acid. Periconceptional daily supplementation of $400 \mu \mathrm{g}$ folic acid (preconceptionally and in the first trimester) has been recommended in Norway since 1998, but compliance is not satisfactory (28). Although $43 \%$ of the preeclampsia women and $74 \%$ of the control women reported taking folic acid at some time point periconceptionally, few pregnant women use folic acid supplementation throughout the pregnancy (28), which is supported by the low maternal folate concentrations found in our study. Vitamin $B_{12}$ has previously been found to be a predictor for maternal tHcy (29); this was also found in our study for the control group, but interestingly, $\mathrm{B}_{12}$ was not a predictor for tHcy in the preeclampsia group.

Plasma creatinine concentration was slightly elevated in the preeclampsia group compared with the control group (Table 2). In accordance with a previous study (8), we found no correlation between thcy and creatinine in the preeclampsia group (Table 3 and Table 4).

Amino acids are transported actively across the placenta, as indicated by higher fetal than maternal concentrations for most amino acids (30). Studies of animal and human models report decreased placental transport of amino acids to the fetus in situations of growth restriction, but not always reduced fetal concentrations $(30,31)$. One study reported increased maternal and fetal amino acid concentrations in preeclampsia compared with controls (32). It has been hypothesized that altered amino acid metabolism in pregnancy is driven by fetal requirements through unknown mechanisms (25). It could be hypothesized that, despite a situation of impaired placental function and flow as in (severe) preeclampsia, the placenta produces and delivers more of the essential nutrient choline to the fetus as a compensatory mechanism, a notion that could be supported by the lack of correlation between maternal and fetal choline.

The concentration of most metabolites and vitamins investigated in our study were moderately (vitamin $\mathrm{B}_{12}$, methionine, cystathionine, and DMG) or markedly (folate, choline, and betaine) higher in the fetal compared with the maternal compartment. Notable exceptions, both in the preeclamptic and control groups, were tHcy and tCys, with lower median concentrations in fetal compared with maternal plasma. High maternal tHcy and tCys are associated with an adverse pregnancy outcome, such as preeclampsia and SGA, both in the present study and previous studies. One could therefore speculate whether there are regulatory mechanisms protecting the fetus from high concentrations of these compounds. The concentration of both compounds, however, are still higher in fetal plasma in preeclampsia than in uncomplicated pregnancy, which has recently also been reported (for tHcy) by others $(33,34)$. In this respect, tHcy and tCys are different from other substances associated with preeclampsia, such as indicators of endothelial dysfunction $(35,36)$, oxidative stress $(37,38)$, and inflammation (18), which have previously been found elevated in the maternal, not in the fetal compartment in preeclamptic pregnancies. Elevated circulating homocysteine or cysteine concentration in preeclamptic pregnancies may have adverse effects on placental function or the fetus or may only represent an epiphenomenon. The question of causality should be addressed in future research, as the answer is related to possible beneficial effects from interventions with B vitamins to lower tHcy.

Folic acid supplementation through pregnancy, and not only periconceptionally, has been found to decrease tHcy (25) and increase birth weight (6) in normal pregnancies. It is not known whether interventions aimed at lowering tHcy concentrations could influence the risk or severity of preeclampsia. A retrospective study from Canada on preeclampsia did not show incidence reduction after implementation of food fortification with folic acid (39), whereas two studies have demonstrated a lower incidence of preeclampsia with multivitamin use $(40,41)$. To our knowledge, no randomized intervention study on tHcy lowering with B vitamins to prevent preeclampsia has been performed.

A strength of this study is that the included subjects are clinically well defined. In addition, all women were fasting, and all deliveries were by cesarean section. As our preeclampsia group underwent cesarean section, they clinically would have more severe preeclampsia and/or have shorter gestational length with unripe cervix compared with the group of preeclamptic women delivered vaginally. Our included preeclampsia group is therefore not representative of all women with preeclampsia, but possibly the most interesting group to 
study, as the premature delivery and more severe preeclampsia have most severe consequences for the infant. Blood samples were carefully collected and preserved from the different compartments, with umbilical cord plasma from arteries and veins separate. One limitation is that the sample size is small; another is that the median gestational age differs between preeclampsia and controls. It is difficult to match for gestational age between the often prematurely delivered preeclamptic patients and women with uncomplicated deliveries, as cesarean section is not done preterm on healthy controls. Several studies have shown that tHcy concentrations are lower in early third trimester than at term; thus, the differences demonstrated in our study between preeclamptics and controls are probably underestimated.

The importance of elevated tHcy or tCys concentrations in maternal and fetal compartments remains to be explored, in relation to both fetal growth and development of disease later in life. To our knowledge, higher concentrations of choline and betaine have not been reported for preeclampsia before or for the maternal or fetal circulation, and these results could prove useful for further research regarding the causes and consequences of elevated homocysteine in preeclampsia, as well as in potential intervention studies.

Acknowledgments. Professor Leif Sandvik at Ulleval University Hospital is gratefully acknowledged for help with the statistical analyses.

\section{REFERENCES}

1. Roberts JM, Redman CW 1993 Pre-eclampsia: more than pregnancy-induced hypertension. Lancet 341:1447-1451

2. Sibai B, Dekker G, Kupferminc M 2005 Pre-eclampsia. Lancet 365:785-799

3. Wilson KM, Lentz SR 2005 Mechanisms of the atherogenic effects of elevated homocysteine in experimental models. Semin Vasc Med 5:163-171

4. Homocysteine Studies Collaboration 2002 Homocysteine and risk of ischemic heart disease and stroke: a meta-analysis. JAMA 288:2015-2022

5. El-Khairy L, Ueland PM, Refsum H, Graham IM, Vollset SE 2001 Plasma total cysteine as a risk factor for vascular disease: the European Concerted Action Project. Circulation 103:2544-2549

6. Murphy MM, Scott JM, Arija V, Molloy AM, Fernandez-Ballart JD 2004 Maternal homocysteine before conception and throughout pregnancy predicts fetal homocysteine and birth weight. Clin Chem 50:1406-1412

7. Malinow MR, Rajkovic A, Duell PB, Hess DL, Upson BM 1998 The relationship between maternal and neonatal umbilical cord plasma homocyst(e) ine suggests a potential role for maternal homocyst(e)ine in fetal metabolism. Am J Obstet Gynecol 178:228-233

8. Powers RW, Evans RW, Majors AK, Ojimba JI, Ness RB, Crombleholme WR, Roberts JM 1998 Plasma homocysteine concentration is increased in preeclampsia and is associated with evidence of endothelial activation. Am J Obstet Gynecol 179:1605-1611

9. Raijmakers MT, Zusterzeel PL, Steegers EA, Hectors MP, Demacker PN, Peters WH 2000 Plasma thiol status in preeclampsia. Obstet Gynecol 95:180-184

10. El-Khairy L, Vollset SE, Refsum H, Ueland PM 2003 Plasma total cysteine, pregnancy complications, and adverse pregnancy outcomes: the Hordaland Homocysteine Study. Am J Clin Nutr 77:467-472

11. Sorensen TK, Malinow MR, Williams MA, King IB, Luthy DA 1999 Elevated second-trimester serum homocyst(e)ine levels and subsequent risk of preeclampsia. Gynecol Obstet Invest 48:98-103

12. Cotter AM, Molloy AM, Scott JM, Daly SF 2001 Elevated plasma homocysteine in early pregnancy: a risk factor for the development of severe preeclampsia. Am J Obstet Gynecol 185:781-785
13. Mignini LE, Latthe PM, Villar J, Kilby MD, Carroli G, Khan KS 2005 Mapping the theories of preeclampsia: the role of homocysteine. Obstet Gynecol 105:411-425

14. Craig SA 2004 Betaine in human nutrition. Am J Clin Nutr 80:539-549

15. Zeisel SH, Niculescu MD 2006 Perinatal choline influences brain structure and function. Nutr Rev 64:197-203

16. Molloy AM, Mills JL, Cox C, Daly SF, Conley M, Brody LC, Kirke PN, Scott JM, Ueland PM 2005 Choline and homocysteine interrelations in umbilical cord and maternal plasma at delivery. Am J Clin Nutr 82:836-842

17. Velzing-Aarts FV, Holm PI, Fokkema MR, van der Dijs FP, Ueland PM, Muskiet FA 2005 Plasma choline and betaine and their relation to plasma homocysteine in normal pregnancy. Am J Clin Nutr 81:1383-1389

18. Braekke K, Holthe MR, Kittelsen N, Fagerhol MK, Staff A 2005 Calprotectin, a marker of inflammation, is elevated in the maternal but not in the fetal circulation in preeclampsia. Am J Obstet Gynecol 193:227-233

19. Johnsen SL, Rasmussen S, Wilsgaard T, Sollien R, Kiserud T 2006 Longitudinal reference ranges for estimated fetal weight. Acta Obstet Gynecol Scand 85:286-297

20. Bohn SK, Smeland S, Sakhi AK, Thoresen M, Russnes KM, Tausjo J, Svilaas A, Svilaas T, Blomhoff R 2005 Post-radiotherapy plasma total glutathione is associated to outcome in patients with head and neck squamous cell carcinoma. Cancer Lett 238:240-247

21. Kelleher BP, Broin SD 1991 Microbiological assay for vitamin B12 performed in 96-well microtitre plates. J Clin Pathol 44:592-595

22. O'Broin S, Kelleher B 1992 Microbiological assay on microtitre plates of folate in serum and red cells. J Clin Pathol 45:344-347

23. Holm PI, Ueland PM, Kvalheim G, Lien EA 2003 Determination of choline, betaine, and dimethylglycine in plasma by a high-throughput method based on normal-phase chromatography-tandem mass spectrometry. Clin Chem 49:286-294

24. ACOG Committee on Practice Bulletins-Obstetrics 2002 ACOG practice bulletin. Diagnosis and management of preeclampsia and eclampsia. Number 33, January 2002. Obstet Gynecol 99:159-167

25. Holmes VA, Wallace JM, Alexander HD, Gilmore WS, Bradbury I, Ward M, Scott JM, McFaul P, McNulty H 2005 Homocysteine is lower in the third trimester of pregnancy in women with enhanced folate status from continued folic acid supplementation. Clin Chem 51:629-634

26. Powers RW, Majors AK, Kerchner LJ, Conrad KP 2004 Renal handling of homocysteine during normal pregnancy and preeclampsia. J Soc Gynecol Investig 11:45-50

27. Ueland PM, Holm PI, Hustad S 2005 Betaine: a key modulator of one-carbon metabolism and homocysteine status. Clin Chem Lab Med 43:1069-1075

28. Braekke K, Staff AC 2003 Periconceptional use of folic acid supplements in Oslo. Acta Obstet Gynecol Scand 82:620-627

29. Molloy AM, Mills JL, McPartlin J, Kirke PN, Scott JM, Daly S 2002 Maternal and fetal plasma homocysteine concentrations at birth: the influence of folate, vitamin B12, and the. Am J Obstet Gynecol 186:499-503

30. Cetin I, Ronzoni S, Marconi AM, Perugino G, Corbetta C, Battaglia FC, Pardi G 1996 Maternal concentrations and fetal-maternal concentration differences of plasma amino acids in normal and intrauterine growth-restricted pregnancies. Am J Obstet Gynecol 174:1575-1583

31. Regnault TR, Friedman JE, Wilkening RB, Anthony RV, Hay WW Jr 2005 Fetoplacental transport and utilization of amino acids in IUGR-a review. Placenta 26 A:S52-S62

32. Evans RW, Powers RW, Ness RB, Cropcho LJ, Daftary AR, Harger GF, Vergona R, Finegold DN 2003 Maternal and fetal amino acid concentrations and fetal outcomes during pre-eclampsia. Reproduction 125:785-790

33. Wang J, Trudinger BJ, Duarte N, Wilcken DE, Wang XL 2000 Elevated circulating homocyst (e) ine levels in placental vascular disease and associated pre-eclampsia. BJOG 107:935-938

34. Ophir E, Dourleshter G, Hirsh Y, Fait V, German L, Bornstein J 2006 Newborns of pre-eclamptic women: a biochemical difference present in utero. Acta Obstet Gynecol Scand 85:1172-1178

35. Friedman SA, Schiff E, Emeis JJ, Dekker GA, Kao L, Sibai BM 1997 Fetal plasma levels of cellular fibronectin as a measure of fetal endothelial involvement in preeclampsia. Obstet Gynecol 89:46-48

36. Krauss T, Azab H, Dietrich M, Augustin HG 1998 Fetal plasma levels of circulating endothelial cell adhesion molecules in normal and preeclamptic pregnancies. Eur J Obstet Gynecol Reprod Biol 78:41-45

37. Braekke K, Harsem NK, Staff AC 2006 Oxidative stress and antioxidant status in fetal circulation in preeclampsia. Pediatr Res 60:560-564

38. Harsem NK, Braekke K, Staff AC 2006 Augmented oxidative stress as well as antioxidant capacity in maternal circulation in preeclampsia. Eur J Obstet Gynecol Reprod Biol 128:209-215

39. Ray JG, Mamdani MM 2002 Association between folic acid food fortification and hypertension or preeclampsia in pregnancy. Arch Intern Med 162:1776-1777

40. Bodnar LM, Tang G, Ness RB, Harger G, Roberts JM 2006 Periconceptional multivitamin use reduces the risk of preeclampsia. Am J Epidemiol 164:470-477

41. Hernandez-Diaz S, Werler MM, Louik C, Mitchell AA 2002 Risk of gestational hypertension in relation to folic acid supplementation during pregnancy. Am J Epidemiol 156:806-812 